\title{
Molecularly Imprinted Chitin Nanofiber Membranes: Multi-Stage Cascade Membrane Separation within the Membrane
}

\author{
Kenta Shiomi and Masakazu Yoshikawa*
}

\author{
Department of Biomolecular Engineering, Kyoto Institute of Technology, Matsugasaki, Kyoto 606-8585, \\ Japan
}

\begin{abstract}
Molecularly imprinted nanofiber membranes were fabricated from chitin and print molecule of phenylalanine derivative by simultaneously applying an alternative molecular imprinting and an electrospinning. The D-enantiomer imprinted nanofiber membrane preferentially incorporated the D-enantiomer and selectively transported D-enantiomer and vice versa. The permselectivity was exponentially increased with the increase in the membrane thickness, implying that multi-stage cascade membrane separation was carried out within the nanofiber membrane. The present study led to the conclusion that a molecularly imprinted nanofiber membrane is one of suitable membrane forms for the separation membrane with relatively high flux and permselectivity.
\end{abstract}

Keywords: Cascade separation, Chitin, Chiral separation, Molecularly imprinted membrane, Molecular imprinting, Multi-stage cascade membrane separation, Nanofiber, Optical resolution.

\section{INTRODUCTION}

Nanofiber membranes, consisting of fibers with diameters less than $1000 \mathrm{~nm}$, give higher porosity [1] and higher surface area [2] comparing with the corresponding usual two dimensional membrane sheets. In membrane separation, the former contributes to high diffusivity of permeant within the membrane and the latter to enhancement of partition (incorporation) of substrate into a given nanofiber membrane [3].

Throughput (flux) and permselectivity are two key factors in membrane separation. In a sense, the former is more important than the latter. However, those two factors often show a trade-off relationship; in other words, the enhancement of flux leads to a concurrent reduction in permselectivity and vice versa. It is indispensable to enhance both factors so that molecularly imprinted membranes can be applied in various industries. Membranologists, such as membrane scientists and membrane engineers, have perceived that this trade-off relationship in membrane separation had been an unsolved problem or an unsolvable one. It is a hard task to simultaneously enhance both membrane performances, such as flux and permselectivity. From this, nanofiber membranes have emerged in membrane separation field to break through the problems mentioned above.

One of the most plausible methods to enhance membrane performance is introduction of specific

*Address correspondence to this author at the Department of Biomolecular Engineering, Kyoto Institute of Technology, Matsugasaki, Kyoto 606-8585, Japan; Tel: 81-75-724-7816; E-mail: masahiro@kit.ac.jp binding site toward substrate to be preferentially separated into membrane. Molecular imprinting is a facile way to introduce such a recognition site into any materials, such as membrane, adsorbent and so on. As for molecular imprinting, there are a couple of methods, such as a conventional pioneering molecular imprinting [4-12] and an alternative molecular imprinting [13-15]. In the present study, such molecular recognition sites were introduced into nanofiber membranes. To this end, molecularly imprinted nanofiber membrane was adopted as a form of separation membrane in the present study.

There are a couple of methods to obtain molecularly imprinted nanofiber membranes; one is encapsulation of molecularly imprinted nanoparticles into nanofibers $[16,17]$ and the other applying an alternative molecular imprinting [18-20]; in other words, simultaneous application of an alternative molecular imprinting and an electrospinning. Herein the latter method was applied to obtain molecularly imprinted nanofiber membranes as previously reported [21-24].

In the previous study on chiral separation with polysulfone nanofiber membrane with alanyl residues as chiral selectors, nanofiber membranes showed chiral separation ability while the corresponding dense membrane hardly showed such ability [25]. The observed permselectivities for nanofiber membranes were not so high but flux values for nanofiber membranes were two to three orders of magnitude higher than those for the corresponding usual dense membranes. From the morphology of nanofiber membrane, it was inferred that multi-stage cascade separation was occurred during membrane transport 
through a nanofiber membrane as schematically shown in Figure 1.

In the present study, molecularly imprinted nanofiber membranes were fabricated from chitin and print molecule, $N$ - $\alpha$-acetyl-D-phenylalanine or $N$ - $\alpha$ acetyl-L-phenylalanine, and membrane performance was studied based on the above speculation.

(a) Simple diffusion through nanofiber membrane

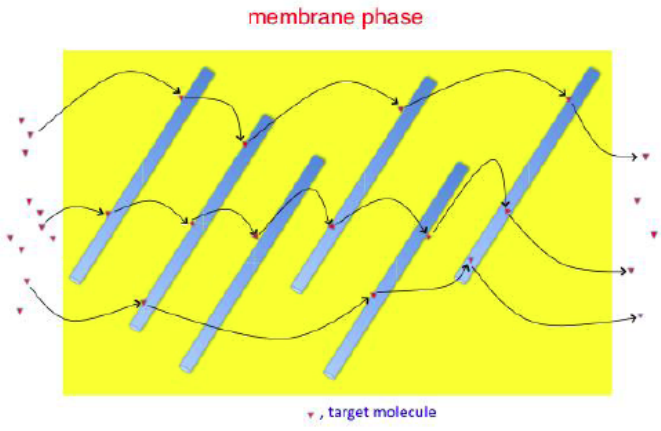

(b) Facilitated transport through nanofiber membrane

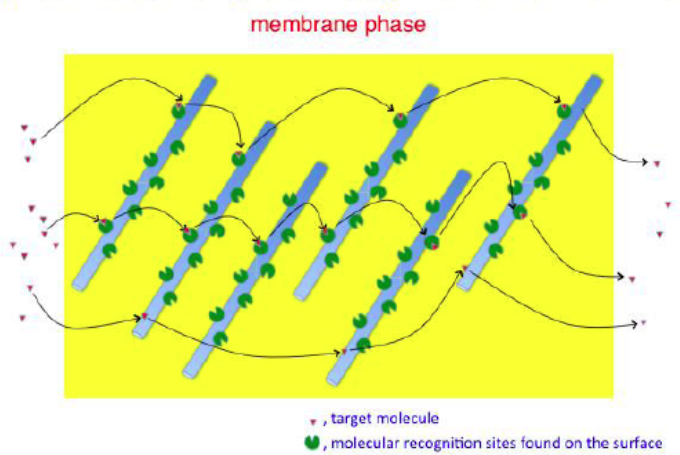

Figure 1: Schematic diagram of membrane transport through nanofiber membrane by simple diffusion (a), and by both facilitated transport and simple diffusion (b).

\section{EXPERIMENTAL}

\subsection{Materials}

Chitin powder from crab shell was purchased from Nacalai Tesque, Inc. Kyoto, Japan. 1,1,1,3,3,3-Hexafluoro-2-propanol (HFIP), $N$ - $\alpha$-acetyl-D-phenylalanine (Ac-D-Phe-OH), $N$ - $\alpha$-acetyl-L-phenylalanine (Ac-L-Phe$\mathrm{OH})$, D-phenylalanine (D-Phe), L-phenylalanine (L-Phe) and sodium azide were obtained from commercial sources and used as received. Water purified with ultrapure water system (Simpli Lab, Millipore S.A., Molsheim, France) was used.

\subsection{Fabrication of Molecularly Imprinted Nanofiber Membranes}

Molecularly imprinted nanofiber membranes were fabricated by simultaneously applying an alternative molecular imprinting and an electrospinning, of which electrospraying conditions were reported previously [23]. HFIP was adopted as a solvent and the polymer concentration was fixed at $0.40 \mathrm{wt} \%$ in the present study. The molecular imprinting ratios, which are ratios of the mole number of print molecule to that of constitutional repeating unit of chitin, were $0.5,1.0$ and 2.0, respectively. Esprayer ES-2000 (Fuence Co. Ltd., Wako, Japan) was adopted as the electrospinning device. Polymer solution containing either one of print molecules was electrosprayed at ambient temperature using an applied voltage of $30.0 \mathrm{kV}$. The syringe used in the present study had a capillary tip of $0.52 \mathrm{~mm}$ diameter. The feeding rate was fixed to be $2.5 \mathrm{~mm}^{3}$ $\min ^{-1}$. A grounded aluminum foil used as a counter electrode was placed $10 \mathrm{~cm}$ from the tip of the capillary. The print molecule was removed from the resultant nanofiber membranes by methanol until the print molecule could be hardly detected in methanol by UV analysis.

The morphology, diameter and thickness $(\delta)$ of the electrosprayed molecularly imprinted nanofiber membranes were determined with S-3000 scanning electron microscope (SEM) (Hitachi High-Technologies Co., Tokyo, Japan). A small section of the membrane sample was placed on the SEM sample holder and sputtered with gold prior to the analysis. The fiber diameter of nanofiber membrane was determined using Image $\mathrm{J}$ software program by measuring 50 fibers from each SEM image.

The conditions for the fabrication of molecularly imprinted nanofiber membranes are summarized in Table 1 together with membrane thickness and diameter.

\subsection{Adsorption Phenomena}

The membrane samples were immersed in a 10.0 $\mathrm{cm}^{3}$ of racemic mixture of Phe aqueous solution with $5.0 \times 10^{-4} \mathrm{~mol} \mathrm{dm}^{-3}$, and the mixture was allowed to be equilibrated at $40{ }^{\circ} \mathrm{C}$. A 0.02 wt. $\%$ sodium azide was added as a fungicide. Quantitative measurements of aliquots of the solution at the initial stage and after equilibrium had been reached were made using liquid chromatography (LC) [JASCO PU-2080, equipped with a UV detector (JASCO UV-2075) (JASCO Co. Hachioji, Japan)] employing a CHIRALPAK MA(+) column (50 $\mathrm{mm} \times 4.6 \mathrm{~mm}$ (i.d.)) (Daicel Co., Osaka, Japan) for the measurement of racemic Phe's. An aqueous copper sulfate/acetonitrile mixed solution was used as a mobile phase. Aliquots of solution after 5 and 10 days 
Table 1: Conditions for Membrane Fabrication ${ }^{\mathrm{a}}$, Membrane Thickness and Fiber Diameter

\begin{tabular}{|c|c|c|c|c|c|c|c|c|c|}
\hline \multirow{2}{*}{$\begin{array}{l}\text { nanofiber } \\
\text { membrane }\end{array}$} & \multicolumn{2}{|c|}{ Chitin } & \multicolumn{2}{|c|}{ Ac-D-Phe-OH } & \multicolumn{2}{|c|}{ Ac-L-Phe } & \multirow{2}{*}{$\begin{array}{c}\text { imprinting } \\
\text { ratiob }^{b}\end{array}$} & \multirow{2}{*}{$\begin{array}{c}10^{4} \delta \\
\mathrm{cm}\end{array}$} & \multirow{2}{*}{$\begin{array}{c}\text { diameter } \\
\mathrm{nm}\end{array}$} \\
\hline & g & mol & g & mol & g & mol & & & \\
\hline \multirow{3}{*}{$\begin{array}{l}\text { Ac-D-Phe-OH } \\
\text { imprinted }\end{array}$} & 0.0800 & $3.94 \times 10^{-4}$ & 0.0409 & $1.97 \times 10^{-4}$ & - & - & 0.5 & 70 & $131 \pm 37$ \\
\hline & 0.0806 & $3.97 \times 10^{-4}$ & 0.0820 & $3.95 \times 10^{-4}$ & - & - & 1.0 & 60 & $95 \pm 33$ \\
\hline & 0.0800 & $3.94 \times 10^{-4}$ & 0.1637 & $7.90 \times 10^{-4}$ & - & - & 2.0 & 95 & $188 \pm 92$ \\
\hline \multirow{3}{*}{$\begin{array}{l}\text { Ac-L-Phe-OH } \\
\text { imprinted }\end{array}$} & 0.0800 & $3.94 \times 10^{-4}$ & - & - & 0.0410 & $1.97 \times 10^{-4}$ & 0.5 & 45 & $138 \pm 81$ \\
\hline & 0.0800 & $3.94 \times 10^{-4}$ & - & - & 0.0817 & $3.94 \times 10^{-4}$ & 1.0 & 70 & $108 \pm 47$ \\
\hline & 0.0802 & $3.95 \times 10^{-4}$ & - & - & 0.1637 & $7.90 \times 10^{-4}$ & 2.0 & 60 & $210 \pm 99$ \\
\hline
\end{tabular}

a $10.0 \mathrm{~cm}^{3}$ of HFIP was adopted as a solvent.

${ }^{b}$ (Ac-Phe-OH) / (Chitin).

were adopted as those of solution. The determined concentrations after 5 days and 10 days gave identical values, which meant the equilibrium has been reached within 5 days.

The adsorption selectivity $S_{A(i j)}$ is defined as

$S_{\mathrm{A}(\mathrm{i} j)}=((\mathrm{i}-\mathrm{Phe}) /(\mathrm{j}-\mathrm{Phe})) /([\mathrm{i}-\mathrm{Phe}] /[\mathrm{j}-\mathrm{Phe}])$

where (i-Phe) and ( $j$-Phe) are the amount of Phe adsorbed in the membrane, and [i-Phe] and [j-Phe] denote the concentrations in the solution after equilibrium had been reached, respectively.

\subsection{Membrane Transport}

A membrane with area of $3.0 \mathrm{~cm}^{2}$ was secured tightly between two chambers of a permeation cell. The volume of each chamber, such as feed side and permeate side, was $40.0 \mathrm{~cm}^{3}$. An aqueous solution of racemic mixture of Phe was placed in the left-hand side chamber (feed side) and an aqueous solution in the right-hand side chamber (permeate side). Each concentration of racemic Phe was fixed to be $1.0 \times 10^{-3}$ $\mathrm{mol} \mathrm{dm}{ }^{-3}$. A $0.02 \mathrm{wt} . \%$ of sodium azide was added as a fungicide. All transport experiments were carried out at $40{ }^{\circ} \mathrm{C}$. The amounts of the D-Phe and L-Phe that transported through the membrane were determined by liquid chromatography (LC) as above.

The flux, $J\left(\mathrm{~mol} \mathrm{~cm} \mathrm{~cm} \mathrm{ch}^{-1}\right)$, is defined as:

$J=\left\{\left(\mathrm{d}[\mathrm{Phe}]_{\mathrm{R}} / \mathrm{d} t\right)\left(V_{\mathrm{R}} / 1000\right) \delta\right\} / A$

where $[\mathrm{Phe}]_{R}\left(\mathrm{~mol} \mathrm{dm} \mathrm{dm}^{-3}\right)$ is the concentration of Phe enantiomer in the right-hand side chamber (permeate side), $t(\mathrm{~h})$ is time, $V_{\mathrm{R}}\left(\mathrm{cm}^{3}\right)$ denotes the volume of the right-hand side chamber, $\delta(\mathrm{cm})$ is membrane thickness and $A\left(\mathrm{~cm}^{2}\right)$ represents membrane area, respectively.
The permselectivity toward i-enantiomer of Phe, $\alpha_{i j}$, is defined as the flux ratio, $J_{\mathrm{i}} / \mathrm{J}_{\mathrm{j}}$, divided by the concentration ratio [i-Phe]/[j-Phe]:

$\alpha_{\mathrm{ij}}=\left(J_{\mathrm{i}} / J_{\mathrm{j}}\right) /([\mathrm{i}-\mathrm{Phe}] /[\mathrm{j}-\mathrm{Phe}])$

\section{RESULTS AND DISCUSSION}

\subsection{Molecularly Imprinted Chitin Nanofiber Membranes}

The scanning electron microscope (SEM) photographs of the electrospun molecularly imprinted chitin nanofiber membranes are shown in Figure 2. In all nanofiber membranes, beads are hardly observed. The diameter and thickness of each nanofiber membrane is summarized in Table 1 together with membrane fabrication conditions. In the present study, strict optimization of conditions for electrospinning was not conducted though the morphology and diameter of nanofiber membranes would be widely controlled by adjusting the electrospinning conditions [26-28].

\subsection{Adsorption Selectivity}

Adsorption selectivities of the present molecularly imprinted nanofiber membranes are summarized in Table 2. In the present study, the amount of Phe adsorbed in the nanofiber membranes was anticipated to be low so that adsorption selectivity was studied at lower concentration of $5.0 \times 10^{-4} \mathrm{~mol} \mathrm{dm}^{-3}$ than that for the membrane transport of $1.0 \times 10^{-3} \mathrm{~mol} \mathrm{dm}^{-3}$. As for the adsorption selectivity of the control chitin nanofiber membrane, it was determined from the adsorption isotherm of Phe in the chitin nanofiber membrane [23]. Both D- and L-enantiomers of Phe were incorporated into the control chitin nanofiber membrane without any specific interaction; in other words, those adsorption isotherms gave straight lines passing through the origin. From this, the control membrane showed 
(a)

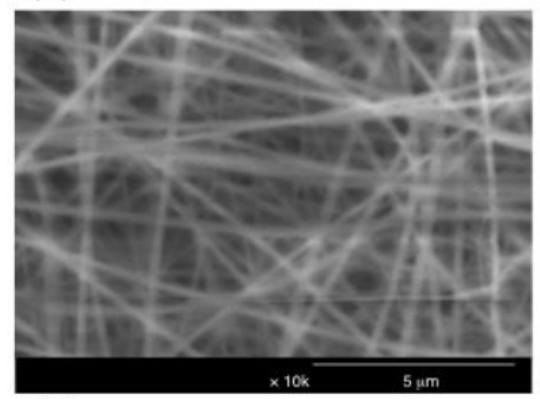

(c)

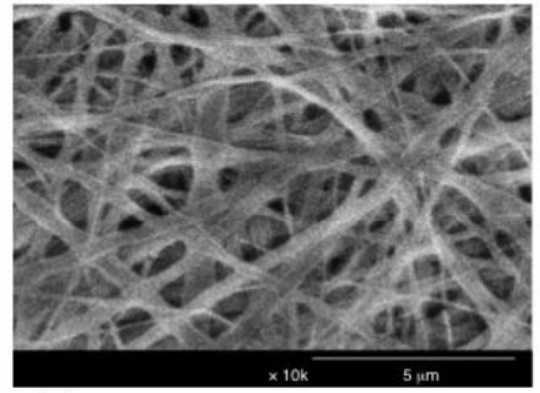

(e)

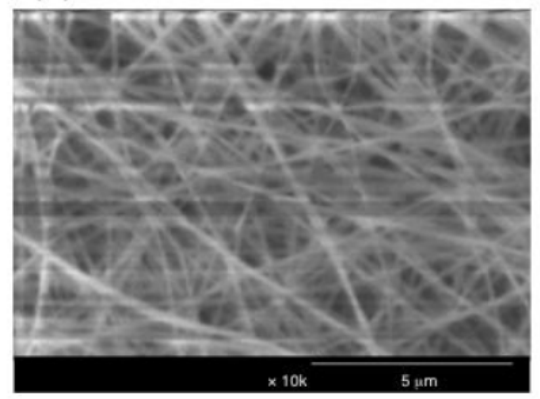

(b)

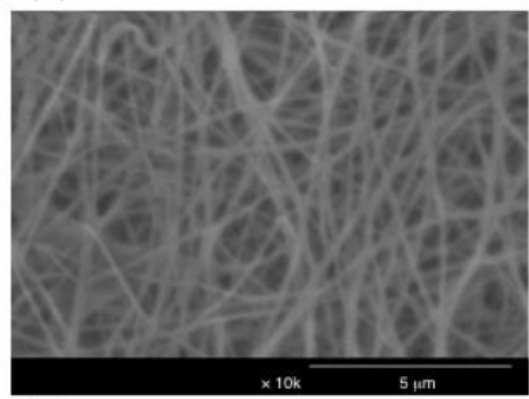

(d)

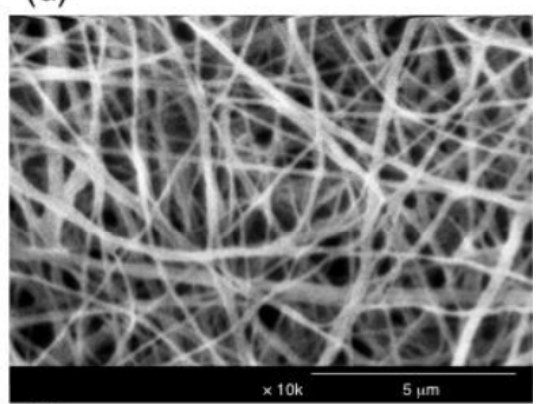

(f)

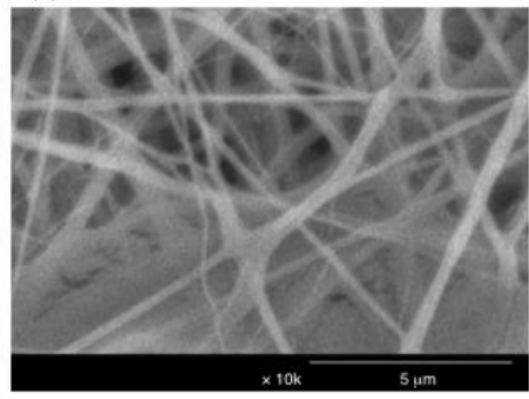

\section{$5 \mu \mathrm{m}$}

Figure 2: SEM images of $A C-D(L)-P h e-O H$ imprinted chitin nanofiber membranes.

(a) Ac-D-Phe-OH imprinted one, imprinting ratio = 0.5; (b) Ac-D-Phe-OH imprinted one, imprinting ratio = 1.0; (c) Ac-D-Phe-OH imprinted one, imprinting ratio $=2.0$; (d) Ac-L-Phe-OH imprinted one, imprinting ratio $=0.5$; (e) Ac-L-Phe-OH imprinted one, imprinting ratio $=1.0 ;(\mathbf{f}) \mathrm{Ac}-\mathrm{L}-\mathrm{Phe}-\mathrm{OH}$ imprinted one, imprinting ratio $=2.0$.

Table 2: Adsorption Selectivity of Molecularly Imprinted Chitin Nanofiber Membranes Toward Racemic Mixture of Phe

\begin{tabular}{|c|c|c|c|c|c|}
\hline \multirow{2}{*}{$\begin{array}{l}\text { nanofiber } \\
\text { membrane }\end{array}$} & \multirow{2}{*}{$\begin{array}{l}\text { imprinting } \\
\text { ratio }^{b}\end{array}$} & \multirow{2}{*}{$\begin{array}{c}\text { D-Phe } \\
{\text { (D-Phe) } /\left(\text { chitin }^{c}\right.}^{c}\end{array}$} & \multirow{2}{*}{$\begin{array}{c}\text { L-Phe } \\
\text { (L-Phe) } /\left(\text { chitin) }^{c}\right.\end{array}$} & \multirow{2}{*}{$S_{A(D / L)}^{d}$} & \multirow{2}{*}{$S_{\mathrm{A}(\mathrm{L} / \mathrm{D})}{ }^{\mathrm{d}}$} \\
\hline & & & & & \\
\hline \multirow{2}{*}{ Ac-D-Phe-OH imprinted } & 0.5 & $4.10 \times 10^{-3}$ & $3.43 \times 10^{-3}$ & 1.22 & 0.82 \\
\hline & 2.0 & $2.52 \times 10^{-3}$ & $2.09 \times 10^{-3}$ & 1.20 & 0.83 \\
\hline \multirow{2}{*}{ Ac-L-Phe-OH imprinted } & 0.5 & $5.98 \times 10^{-3}$ & $7.20 \times 10^{-3}$ & 0.82 & 1.22 \\
\hline & 2.0 & $2.60 \times 10^{-3}$ & $3.18 \times 10^{-2}$ & 0.83 & 1.21 \\
\hline control $^{e}$ & - & $1.30 \times 10^{-3}$ & $1.71 \times 10^{-3}$ & 0.76 & 1.31 \\
\hline
\end{tabular}

${ }^{\mathrm{a}}[\mathrm{D}-\mathrm{Phe}]_{0}=[\mathrm{L}-\mathrm{Phe}]_{0}=5.0 \times 10^{-4} \mathrm{~mol} \mathrm{dm}^{-3} ; \mathrm{NaN}_{3}, 0.02 \mathrm{wt} \%$.

${ }^{b}($ Ac-Phe-OH $) /(\text { chitin })^{c}$

${ }^{c}$ Mole number of constitutional repeating unit of chitin.

${ }^{d} S_{A(i j)}=((i-P h e) /(j-P h e)) /([i-P h e] /[j-P h e])(i=D, j=L$ or $i=L, j=D)$

${ }^{\mathrm{e}}$ Non-imprinted chitin nanofiber membrane. 
constant adsorption selectivity of 1.31 . The ratio of the amount of Phe adsorbed in the membrane to that of constitutional repeating unit of chitin was elucidated from the adsorption isotherm [23].

In the case of alterative molecular imprinting of oligopeptide derivatives, the nature of the molecular recognition sites were dependent on the combination of the absolute configuration of the print molecule and that of constituting amino acid residues; in other words, the print molecule, of which absolute configuration was identical with that of amino acid residue, worked well as a print molecule, and the antipode worked as a porogen [29]. In the case of cellulose triacetate, the Lenantiomer worked well as a print molecule but the Denantiomer did not work well, which was due to the fact that cellulose triacetate consists of $\beta(1 \rightarrow 4)$ linked $D$ glucose [24]. Contrary to the previous study [24], both enantiomers, such as D- and L-enantiomer of Ac-Phe$\mathrm{OH}$, worked well as print molecules toward chitin, though chitin consists of $\mathrm{N}$-acetylglucosamine units, which are connected $\beta-1,4$ linkage. Nanofiber membranes imprinted by Ac-D-Phe-OH showed Denantiomer adsorption selectivity and vice versa like molecularly imprinted membranes from cellulose acetate [22,30], oligopeptide tweezers [31] and chiral polyurea [32-35]. In the case of molecularly imprinted membranes from synthetic polymers with no chiral center, both enantiomers worked well as print molecules [36,37], as expected.

In both D- and L-enantiomer molecularly imprinted nanofiber membranes, the membrane fabricated by the imprinting ratio of 1.0 gave higher adsorption selectivities among present membranes. This is due to as follows: the nanofiber membrane with imprinting

(a)

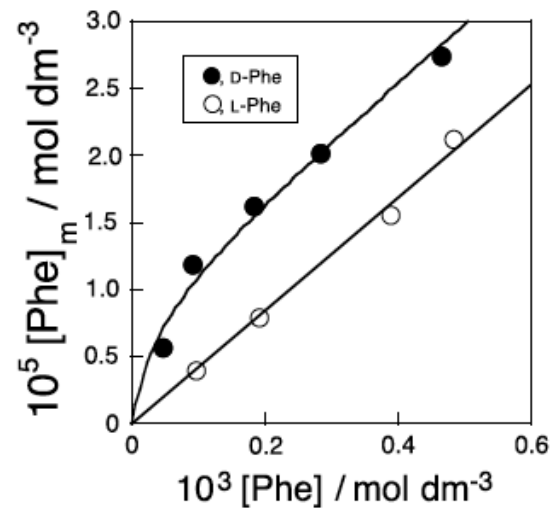

ratio of 1.0 gave narrower fiber diameter among them. This led to that the surface area of the membrane with imprinting ratio of 1.0 showed the highest one, which meant the amount of molecular recognition site was increased. Increase in the amount of print molecule during the membrane fabrication process, in other words, increase in molecular imprinting ratio led to decrease in affinity of molecular recognition site toward the target molecule [38]. From this, the membrane prepared by the imprinting ratio of 2.0 showed lower adsorption selectivity than that by the imprinting ratio of 1.0 .

From the fact that molecularly imprinted nanofiber membranes showed adsorption selectivity, it was thought that molecular recognition sites toward the print molecule and print molecule analogues were constructed in the molecularly imprinted nanofiber membranes. This was confirmed by the adsorption isotherms of the membranes fabricated by the imprinting ratio of 0.5 .

The adsorption isotherms are shown in Figure 3. Enantiomer, of which absolute configuration is opposite to that of print molecule adopted for the fabrication of molecularly imprinted nanofiber membrane, gave a straight line passing through the origin, implying that such enantiomer was adsorbed in the membrane nonspecifically without any specific interaction. The adsorption isotherm of L-Phe for the Ac-D-Phe-OH imprinted nanofiber membrane and that of $D$-Phe for the Ac-L-Phe-OH imprinted one can be represented by the following equation:

$[j-P h e]_{m}=k_{A}[j-P h e]$

(b)

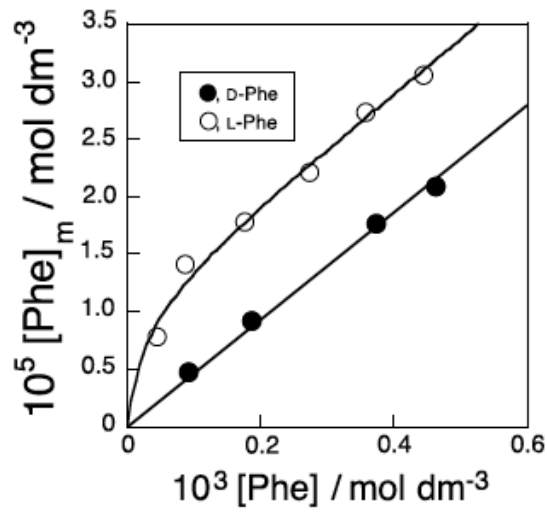

Figure 3: Adsorption isotherms of Phe for AC-D-Phe-OH imprinted nanofiber membrane (a) and Ac-L-Phe-OH imprinted one (b) at $40{ }^{\circ} \mathrm{C}$. (imprinting ratio, 0.5.) 
where $[j-P h e]_{m}$ denotes the enantiomer of Phe nonspecifically adsorbed in the nanofiber membrane, $k_{\mathrm{A}}$ is adsorption constant and [j-Phe] means the concentration of $\mathrm{j}-\mathrm{Phe}$ in the solution equilibrated with the nanofiber membrane.

The adsorption isotherm of D-Phe for the Ac-D-Phe$\mathrm{OH}$ imprinted nanofiber membrane and that of L-Phe for the Ac-L-Phe-OH imprinted one exhibit dual adsorption isotherms, consisting of non-specific adsorption and adsorption on specific recognition sites toward the target molecule. The adsorption isotherm of the enantiomer of Phe preferentially incorporated into the nanofiber membrane can be represented by the following equation:

$[i-\mathrm{Phe}]_{\mathrm{m}}=k_{\mathrm{A}}[i-\mathrm{Phe}]+K_{\mathrm{S}}[\text { Site }]_{0}[i-\mathrm{Phe}] /\left(1+K_{\mathrm{S}}[i-\mathrm{Phe}]\right)(6)$

where $[i-P h e]_{m}$ denotes the concentration of the enantiomer of Phe preferentially incorporated into the nanofiber membrane, $K_{\mathrm{S}}$ is the affinity constant between molecular recognition site and i-Phe, [Site $]_{0}$ is the concentration of molecular recognition site in the membrane and [i-Phe] means the concentration of $i-$ Phe in the solution equilibrated with the membrane.

Two parameters in eqs. (5) and (6), which were determined to fit each adsorption isotherm best, are summarized in Table 3 together with the concentration of molecular recognition site in the membrane. The parameters for the Ac-D-Phe-OH imprinted nanofiber membrane were those with the thickness of $7.0 \times 10^{-3}$ $\mathrm{cm}$ and those for the Ac-L-Phe-OH imprinted membrane were those with the thickness of $4.5 \times 10^{-3}$ $\mathrm{cm}$, respectively. In the coming section, calculations will be done adopting concentrations of molecular recognition site given in the table. As observed in the previous study on molecularly imprinted nanofiber membranes from cellulose acetate [22] and cellulose triacetate [24], the concentration of molecular recognition site in the molecularly imprinted chitin nanofiber membrane was determined to be very low.

Table 3: Parameters for Adsorption Isotherms of Molecularly Imprinted Chitin Nanofiber Membranes $^{a}$

\begin{tabular}{|c|c|c|c|}
\hline \multirow{2}{*}{ membrane } & \multirow{2}{*}{$\boldsymbol{k}_{\mathbf{A}}$} & {$[\text { Site }]_{\mathbf{0}}$} & $\boldsymbol{K}_{\mathbf{S}}$ \\
\cline { 3 - 4 } & & $\mathbf{m o l ~ d m}^{-3}$ & $\mathbf{m o l}^{-1} \mathbf{d m}^{3}$ \\
\hline \hline Ac-D-Phe-OH imprinted & 4.21 & $9.36 \times 10^{-6}$ & $2.52 \times 10^{4}$ \\
\hline Ac-L-Phe-OH imprinted & 4.65 & $1.09 \times 10^{-5}$ & $3.79 \times 10^{4}$ \\
\hline
\end{tabular}

${ }^{\mathrm{a}}$ molecular imprinting ratio, 0.5 .
As discussed in the previous study [22], most print molecule was solely sprayed toward the counter electrode of grounded aluminum foil accompanying with no chitin molecule during electrospinning process. As a result, small amount of the print molecule was electrosprayed together with chitin molecule toward collector. From this, actual molecular imprinting ratio, which was defined as the ratio of the mole number of print molecule to that of constitutional repeating unit of chitin was lower than that for the feed polymer solution.

\subsection{Enantioselective Transport of Racemic Mixture of Phe}

From the study on adsorption selectivity, those two types of molecularly imprinted nanofiber membrane were expected to show optical resolution ability. To this end, enantioselective transport of racemic mixture of Phe with those membranes was studied.

The membrane performances for the present membranes are summarized in Table 4. Each molecularly imprinted nanofiber membrane showed permselectivity, reflecting its adsorption selectivity, while the permselectivity of the control non-imprinted nanofiber membrane was opposite to its adsorption selectivity.

Adsorption study and membrane transport study revealed that molecularly imprinted chitin nanofiber membranes were kinds of fixed carrier membrane. As shown in Figure 1, the permselectivity through the nanofiber membrane would be enhanced with the increase in thickness of nanofiber membrane. In other words, the target molecule interacted with molecularly imprinted nanofibers, and as a result, permselectivity would be enhanced like multi-stage cascade membrane separation [23,39-41]. To this end, three types of molecularly imprinted nanofiber membrane with different membrane thickness were fabricated from chitin and Ac-D-Phe-OH or Ac-L-Phe-OH, of which imprinting ratio being 0.5 , and their membrane performances were studied.

The membrane performances for those three types of nanofiber membrane with the imprinting ratio of 0.5 are summarized in Table $\mathbf{4}$ together with those for other membranes. As expected, the permselectivity toward the target molecule increased with the increase in membrane thickness. The relationship between permselectivity and membrane thickness is shown in Figure 4. 
Table 4: Membrane Performances of Molecularly Imprinted Chitin Nanofiber Membranes ${ }^{\mathrm{a}}$

\begin{tabular}{|c|c|c|c|c|c|c|}
\hline \multirow{2}{*}{ Membrane } & \multirow{2}{*}{$\begin{array}{l}\text { imprinting } \\
\text { ratio }\end{array}$} & \multirow{2}{*}{$\frac{10^{4} \delta}{\mathrm{cm}}$} & \multirow{2}{*}{$\begin{array}{c}J_{D} \\
\mathrm{~mol} \mathrm{~cm} \mathrm{~cm} \mathrm{~cm}^{-2} \mathrm{~h}^{-1}\end{array}$} & \multirow{2}{*}{$\frac{J_{\mathrm{L}}}{\mathrm{mol} \mathrm{cm} \mathrm{cm}^{-2} \mathrm{~h}^{-1}}$} & \multirow{2}{*}{$\alpha_{\mathrm{D} / \mathrm{L}}$} & \multirow{2}{*}{$\alpha_{\mathrm{L} / \mathrm{D}}$} \\
\hline & & & & & & \\
\hline \multirow{5}{*}{ Ac-D-Phe-OH imprinted } & 0.5 & 40 & $1.88 \times 10^{-9}$ & $1.83 \times 10^{-9}$ & 1.03 & 0.97 \\
\hline & 0.5 & 70 & $1.50 \times 10^{-9}$ & $1.42 \times 10^{-9}$ & 1.06 & 0.95 \\
\hline & 0.5 & 100 & $1.67 \times 10^{-9}$ & $1.53 \times 10^{-9}$ & 1.09 & 0.92 \\
\hline & 1.0 & 60 & $2.45 \times 10^{-9}$ & $2.20 \times 10^{-9}$ & 1.11 & 0.90 \\
\hline & 2.0 & 95 & $2.05 \times 10^{-9}$ & $1.90 \times 10^{-9}$ & 1.08 & 0.93 \\
\hline \multirow{5}{*}{ Ac-L-Phe-OH imprinted } & 0.5 & 45 & $2.15 \times 10^{-9}$ & $2.22 \times 10^{-9}$ & 0.97 & 1.03 \\
\hline & 0.5 & 85 & $2.04 \times 10^{-9}$ & $2.15 \times 10^{-9}$ & 0.95 & 1.05 \\
\hline & 0.5 & 220 & $1.85 \times 10^{-9}$ & $2.13 \times 10^{-9}$ & 0.87 & 1.15 \\
\hline & 1.0 & 70 & $2.02 \times 10^{-9}$ & $2.19 \times 10^{-9}$ & 0.92 & 1.08 \\
\hline & 2.0 & 60 & $1.29 \times 10^{-9}$ & $1.37 \times 10^{-9}$ & 0.94 & 1.06 \\
\hline control $^{b}$ & - & 250 & $2.27 \times 10^{-9}$ & $1.85 \times 10^{-9}$ & 1.23 & 0.81 \\
\hline
\end{tabular}

${ }^{a}[D-P h e]_{L, 0}=[L-P h e]_{L, 0}=1.0 \times 10^{-3} \mathrm{~mol} \mathrm{dm}^{-3} ; \mathrm{NaN}_{3}=0.02 \mathrm{wt} . \%$.

${ }^{\mathrm{b}}$ cited from ref. [23].

(a)

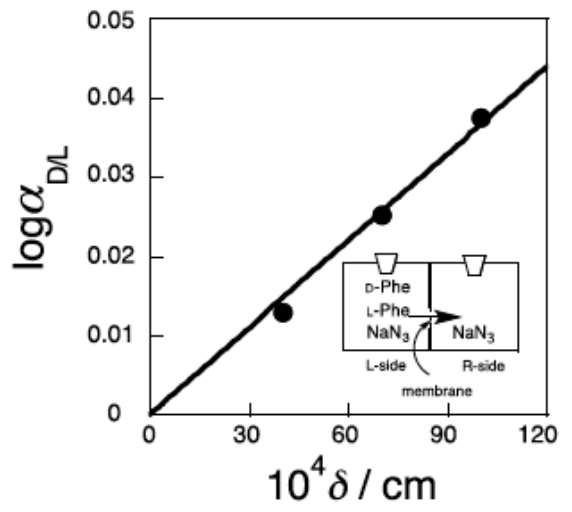

(b)

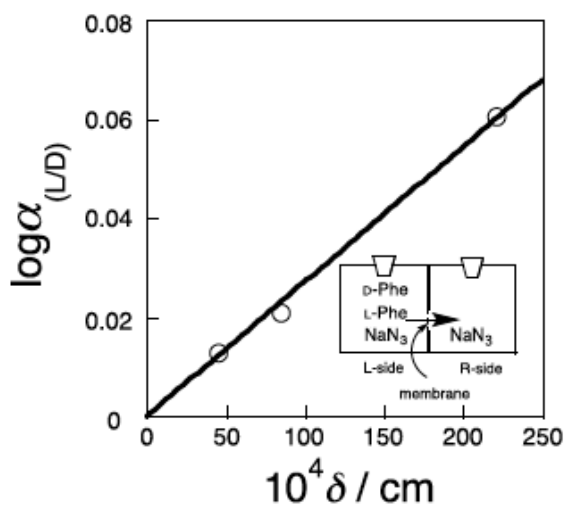

Figure 4: Dependence of membrane performance of molecularly imprinted nanofiber membranes on membrane thickness.

(Ac-D-Phe-OH imprinted membrane (a); Ac-L-Phe-OH imprinted imprinted one $(\mathbf{b})$; imprinting ratio, $0.5 ;[D-P h e]_{L, 0}=[L-P h e]_{L, 0}=$ $1.0 \times 10^{-3} \mathrm{~mol} \mathrm{dm}^{-3} ; \mathrm{NaN}_{3}, 0.02$ wt. \%).

In Figure 4, the logarithm of permselectivity is plotted as a function of membrane thickness. As can be seen, the logarithm of permselectivity is proportional to membrane thickness. The observed relationship will be interpreted as follows: diagram for the schematic representation of molecularly imprinted nanofiber membrane (fixed carrier membrane) is shown in Figure 5. The number of fixed carriers (molecular recognition sites) aligned from the feed side to the permeate side is assumed to be $n$. Assuming that molecular recognition sites are aligned with an equal distance of $\lambda$, the number of $n$ can be represented by:

$n=\delta / \lambda$
The volume occupied by one molecular recognition site in the membrane $v$ can be represented as follows:

$v=A \delta / N$

where $N$ is the total amount of molecular recognition site in the membrane. $A$ and $\delta$ are defined as before, membrane area and membrane thickness, respectively. From eq. (8), the distance between adjacent molecular recognition sites is represented by:

$\lambda=v^{1 / 3}=(A \delta / N)^{1 / 3}$

Substituting the above expression in eq. (7) yields the following equation: 


\section{$\leftarrow$ Membrane thickness $(\delta) \rightarrow$}

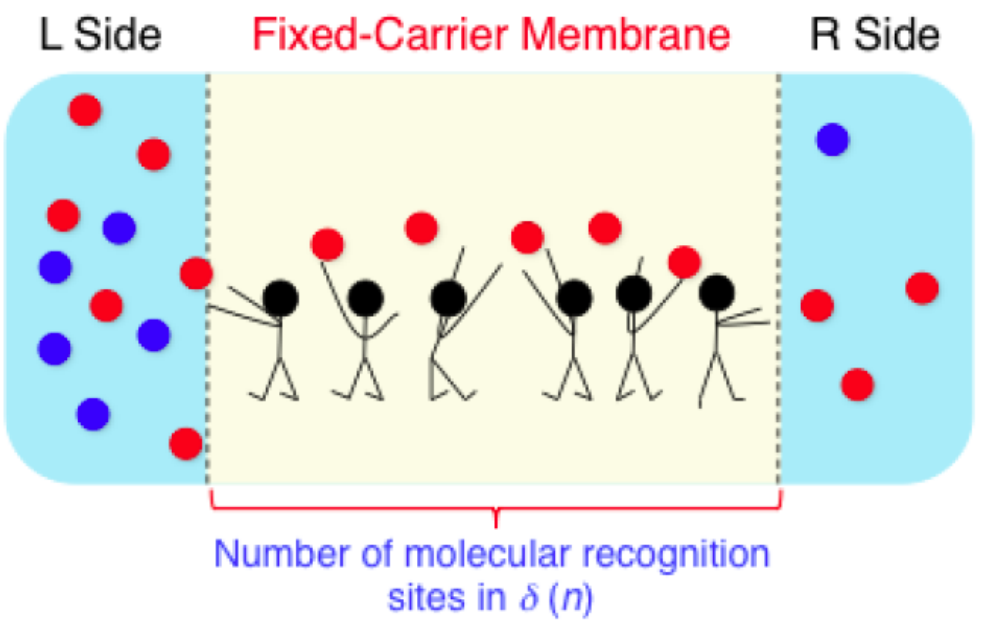

Figure 5: Diagram of fixed carrier membrane.

$n=\delta /(A \delta / N)^{1 / 3}$

Assuming that the permselectivity expressed by one

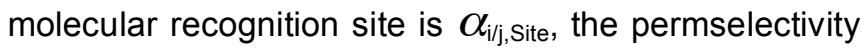
expressed by the transport through the membrane is represented by eq. (11):

$\alpha_{\mathrm{i} j \mathrm{j}, s}=\left(\alpha_{\mathrm{ij}, \mathrm{Site}}\right)^{\mathrm{n}}=\left(\alpha_{\mathrm{ij}, 1 \mathrm{~cm}}\right)^{\delta}$

where $\alpha_{\mathrm{ij}, 1 \mathrm{~cm}}$ denotes permselectivity expressed by the membrane with thickness of $1 \mathrm{~cm}$.

Eq. (11) yields eq. (12).

$\log \left(\alpha_{\mathrm{ij} j, \delta}\right)=\left(\log \left(\alpha_{\mathrm{i} j, \mathrm{Site}}\right)\right) \times n=\left(\log \left(\alpha_{\mathrm{ij}, 1 \mathrm{~cm}}\right)\right) \times \delta$

Eq. (12) means that the permselectivity will be increased with the increase in membrane thickness; in other words, the increase in number of interaction between the target molecule and molecular recognition site leads to enhancement of permselectivity. The validity of eq. (12) was confirmed by the relationships shown in Figure 4.

The slope for each plot was determined to be 3.7 for the D-enantiomer imprinted nanofiber membrane (Figure 4a) and 2.7 for the L-enantiomer one (Figure 4b). From the slopes, the imaginary permselectivity for each membrane with thickness of $1 \mathrm{~cm}$ was determined to be $5.0 \times 10^{3}$ and $5.0 \times 10^{2}$, respectively. However, as shown in Figure 6, the flux value was deceased linearly with the decrease in reciprocal of membrane thickness; in other words, the flux was decreased with the increase in membrane thickness. From this, such high imaginary permselectivity of over 500 would not be obtained in the reality.

(b)
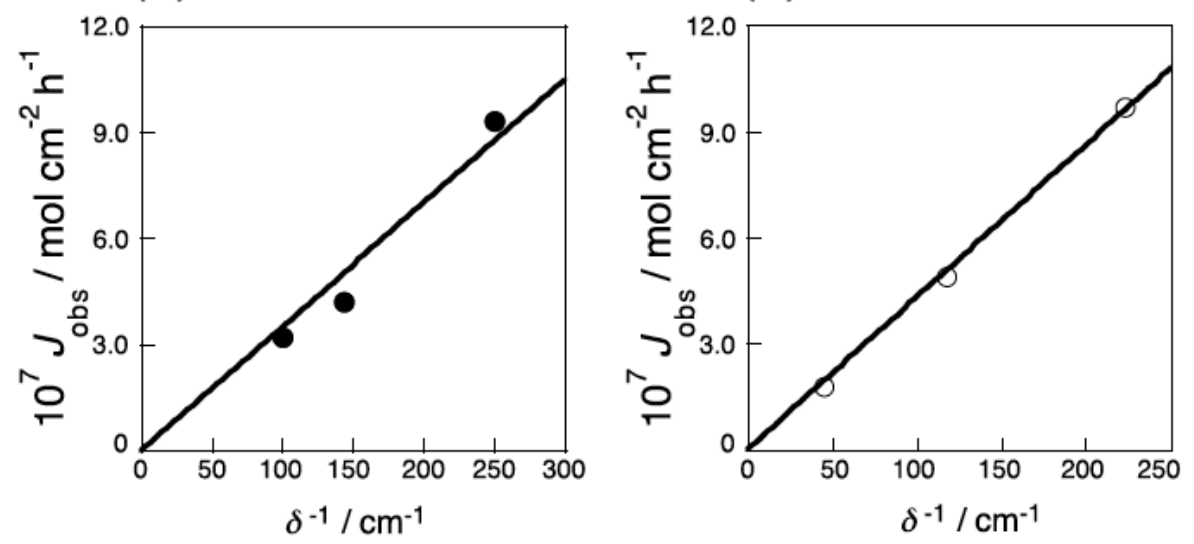

Figure 6: Relationship between flux and reciprocal of membrane thickness. (Ac-D-Phe-OH molecularly imprinted membrane (a); Ac-L-Phe-OH imprinted one (b)). 
The distance $\lambda$ can be determined from the concentration of molecular recognition site, which was determined from adsorption isotherm. From those values, $\lambda$ for each membrane was determined to be 5.6 $x 10^{-6} \mathrm{~cm}$ for the D-enantiomer imprinted nanofiber membrane and $5.3 \times 10^{-6} \mathrm{~cm}$ for the L-enantiomer imprinted one, respectively. From those distances, the permselectivity expressed by one molecular recognition site for the D-enantiomer imprinted nanofiber membrane was determined to be 1.00005 and that for the L-enantiomer imprinted one to be 1.00003, respectively. Though the permselectivity expressed by one molecular recognition site was very low, the target molecule interacted so many times with the specific binding (molecular recognition) site while the target molecule migrated from the feed side to the permeate side. As a result, permselectivity was exponentially enhanced from permselectivity, which was limitlessly close to unity, to significantly over unity.

The present study revealed that the most suitable membrane separation is a multistage-cascade membrane separation with nanofiber or molecularly imprinted nanofiber membranes.

\section{CONCLUSIONS}

Molecularly imprinted nanofiber membranes were fabricated from chitin and print molecule of phenylalanine derivative by simultaneously applying molecular imprinting and electrospinning. The Denantiomer imprinted nanofiber membrane preferentially incorporated the D-enantiomer and vice versa. The affinity constant between D-enantiomer recognition site and D-Phe was determined to be $2.52 \mathrm{x}$
$10^{4} \mathrm{~mol}^{-1} \mathrm{dm}^{3}$ and that between L-enantiomer recognition site and L-Phe to be $3.79 \times 10^{4} \mathrm{~mol}^{-1} \mathrm{dm}^{3}$, respectively. The D-enantiomer imprinted nanofiber membrane selectively transported D-enantiomer and vice versa. The permselectivity was increased exponentially with the increase in the membrane thickness, implying that multi-stage cascade separation was carried out within the nanofiber membrane. The present study led to the conclusion that a molecularly imprinted nanofiber membrane is one of suitable membrane form for the separation membrane with relatively high flux and permselectivity.

\section{APPENDIX}

It is interesting and indispensable to study the permselectivity for usual dense membrane bearing a fixed carrier (a molecular recognition site). Here, the usual dense membrane is defined as the ideal dense membrane having no defect; in other words, the membrane morphology within the membrane is uniformly homogeneous from the feed side to the permeate side without defect.

As depicted in Figure 7, the number of fixed carriers (molecular recognition sites) aligned from the feed side to the permeate side is assumed to be $n$. For convenience' sake, the fixed carriers were aligned at equal distance. From this, the membrane is divided into $n$ layers at equal distance as can be seen in Figure 7 .

The equation for flux at steady state through the membrane will be described so that the permselectivity can be derived. The steady state flux for the given target molecule, which is transported by both facilitated

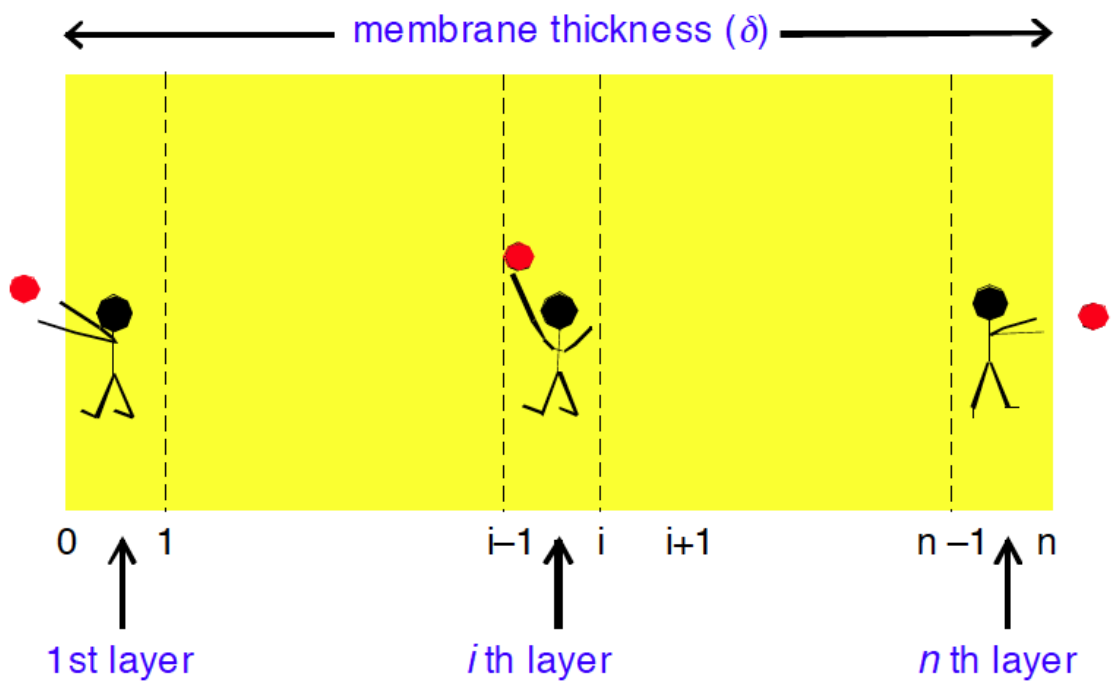

Figure 7: Diagram of membrane transport through a fixed carrier membrane. 


$$
\begin{aligned}
& (\delta / n) J_{\mathrm{L}, 1}=D_{\mathrm{A}, \mathrm{L}}\left(k_{\mathrm{A}, \mathrm{L}}[\mathrm{L}]_{0}-[\mathrm{L}]_{1}\right)+D_{\mathrm{S}, \mathrm{L}}\left(\frac{k_{\mathrm{A}, \mathrm{L}} K_{\mathrm{S}, \mathrm{L}}[\mathrm{Site}]_{0}[\mathrm{~L}]_{0}}{1+k_{\mathrm{A}, \mathrm{L}} K_{\mathrm{S}, \mathrm{L}}[\mathrm{L}]_{0}}-\frac{K_{\mathrm{S}, \mathrm{L}}[\mathrm{Site}]_{1}[\mathrm{~L}]_{1}}{1+K_{\mathrm{S}, \mathrm{L}}[\mathrm{L}]_{1}}\right) \\
& +\quad(\delta / n) J_{\mathrm{L}, \mathrm{n}}=D_{\mathrm{A}, \mathrm{L}}\left([\mathrm{L}]_{\mathrm{n}-1}-k_{\mathrm{A}, \mathrm{L}}[\mathrm{L}]_{\mathrm{n}}\right)+D_{\mathrm{S}, \mathrm{L}}\left(\frac{K_{\mathrm{S}, \mathrm{L}}[\mathrm{Site}]_{\mathrm{n}-1}[\mathrm{~L}]_{\mathrm{n}-1}}{1+K_{\mathrm{S}, \mathrm{L}}[\mathrm{L}]_{\mathrm{n}-1}}-\frac{k_{\mathrm{A}, \mathrm{L}} K_{\mathrm{S}, \mathrm{L}}[\mathrm{Site}]_{\mathrm{n}}[\mathrm{L}]_{n}}{1+k_{\mathrm{A}, \mathrm{L}} K_{\mathrm{S}, \mathrm{L}}[\mathrm{L}]_{\mathrm{n}}}\right) \\
& \delta J_{\mathrm{L}}=D_{\mathrm{A}, \mathrm{L}} k_{\mathrm{A}, \mathrm{L}}\left([\mathrm{L}]_{0}-[\mathrm{L}]_{\mathrm{n}}\right)+D_{\mathrm{S}, \mathrm{L}}\left(\frac{k_{\mathrm{A}, \mathrm{L}} K_{\mathrm{S}, \mathrm{L}}[\mathrm{Site}]_{0}[\mathrm{~L}]_{0}}{1+k_{\mathrm{A}, \mathrm{L}} K_{\mathrm{S}, \mathrm{L}}[\mathrm{L}]_{0}}-\frac{k_{\mathrm{A}, \mathrm{L}} K_{\mathrm{S}, \mathrm{L}}[\mathrm{Site}]_{n}[\mathrm{~L}]_{\mathrm{n}}}{1+k_{\mathrm{A}, \mathrm{L}} K_{\mathrm{S}, \mathrm{L}}[\mathrm{L}]_{\mathrm{n}}}\right) \\
& \delta J_{\mathrm{D}}=D_{\mathrm{A}, \mathrm{D}} k_{\mathrm{A}, \mathrm{D}}\left([\mathrm{D}]_{0}-[\mathrm{D}]_{\mathrm{n}}\right) \\
& \alpha_{\mathrm{L} / \mathrm{D}}=\frac{D_{\mathrm{A}, \mathrm{L}} k_{\mathrm{A}, \mathrm{L}}\left([\mathrm{L}]_{0}-[\mathrm{L}]_{\mathrm{n}}\right)+D_{\mathrm{S}, \mathrm{L}}\left(\frac{k_{A, L} K_{\mathrm{S}, \mathrm{L}}[\mathrm{Site}]_{0}[\mathrm{~L}]_{0}}{1+k_{A, L} K_{\mathrm{S}, \mathrm{L}}[\mathrm{L}]_{0}}-\frac{k_{A, L} K_{\mathrm{S}, \mathrm{L}}[\mathrm{Site}]_{\mathrm{n}}[\mathrm{L}]_{\mathrm{n}}}{1+k_{\mathrm{A}, \mathrm{L}} K_{\mathrm{S}, \mathrm{L}}[\mathrm{L}]_{\mathrm{n}}}\right)}{D_{\mathrm{A}, \mathrm{D}} K_{\mathrm{A}, \mathrm{D}}\left([\mathrm{D}]_{0}-[\mathrm{D}]_{\mathrm{n}}\right)}
\end{aligned}
$$

transport and simple diffusion, through the first layer can be represented by eq. (13). $J_{\mathrm{L}, 1}$ denotes the flux through the 1 st layer at the steady state. Therefore, the flux through individual layer $J_{\mathrm{L}, \mathrm{i}}$ is identical to $J_{\mathrm{L}}$, which is a flux through the the given membrane from the feed side to the permeate side. The flux through the ith layer can be represented by eq. (14), and that through the last layer ( $n$th layer) by eq. (15). Eq. (16) is obtained by summing up whole equations representing the flux for each layer, such as eqs. (13), (14), (15) and so on. As a result, the flux of target molecule through the membrane is represented by eq. (16). If the target molecule is the L-enantiomer, the flux of the target molecule L-enantiomer is expressed by eq. (16).

The flux of antipode, D-enantiomer, which is transported through the membrane by just simple diffusion, is represented by eq. (17).

The permselectivity for membrane transport of racemic mixture of $\mathrm{D}$-and L-enantiomers is represented by eq. (18). Contrary to permselectivity observed by molecularly imprinted nanofiber membrane, the permselectivity expressed by the ideal dense membrane with fixed carrier will be independent of number of interactions $(n)$ between molecular recognition site and the target molecule.
The above result is applicable to an ideal dense membrane. In a real case, there might be found defects within the dense membrane, which might lead to a certain degree of enhancement of permselectivity with the increase in $n$.

\section{REFERENCES}

[1] Chu B, Hsiao BS. The role of polymers in breakthrough technologies for water purification. J Polym Sci: Part B: Polym Phys 2009; 47: 2431-5. http://dx.doi.org/10.1002/polb.21854

[2] Gibson P, Schreuder-Gibson H, Rivin D. Transport properties of porous membranes based on electrospun nanofibers. Colloids Surf A 2001; 187-188: 469-81. http://dx.doi.org/10.1016/S0927-7757(01)00616-1

[3] In the case of nanofiber membrane, its morphology is porous. From this, incorporation of substrate into the membrane is called "partition" rather than "solution" in the present study.

[4] Polyakov MV. Adsorption properties of silica gel and its structure. Zhur Fiz Khim 1931; 2: 799-805.

[5] Dickey FH. The preparation of specific adsorbents. Proc Natl Acd Sci USA 1949; 35: 227-9. http://dx.doi.org/10.1073/pnas.35.5.227

[6] Dickey FH. Specific adsorption. J Phys Chem 1955; 59: 695707. http://dx.doi.org/10.1021/j150530a006

[7] Wulff G, Sarhan A. The use of polymers with enzymeanalogous structures for the resolution of racemates. Angew Chem Int Ed 1972; 11: 341. DOI: 10.1002/anie.197203341

[Über die anwendung von enzyme gebauten polymeren zur racemettrennung. Angew Chem 1972; 84: 364]. DOI: 10.1002/ange. 19720840838 
[8] Bartsch RA, Maeda M, Eds. Molecular and ionic recognition with imprinted polymers (ACS Symposium Series 703). Washington DC: ACS 1998.

[9] Haupt K, Mosbach K. Molecularly imprinted polymers and their use in biomimetic sensors. Chem Rev 2000; 100: 2495-504. http://dx.doi.org/10.1021/cr990099w

[10] Sellergren B Ed. Molecularly imprinted polymers. Man-made mimics of antibodies and their applications in analytical chemistry. Amsterdam: Elsevier 2000.

[11] Alexander C, Andersson LI, Ansell RJ, Kirsch N, Nicholls IA, O'Mahony $\mathrm{J}$, Whitcombe MJ. Molecular imprinting science and technology: a survey of the literature for the years up to and including 2003. J Mol Recognit 2006; 19: 106-80. http://dx.doi.org/10.1002/jmr.760

[12] Whitcombe MJ, Kirsch N, Nicholls IA. Molecular imprinting science and technology: a survey of the literature for the years 2004-2011. J Mol Recognit 2014; 27: 297-401. http://dx.doi.org/10.1002/jmr.2347

[13] Michales AS, Baddour RF, Bixler HJ, Choo CY. Conditioned polyethylene as a permselective membrane Separation of isomeric xylenes. Ind Eng Chem Process Des Dev 1962; 1: 14-25.

http://dx.doi.org/10.1021/i260001a003

[14] Yoshikawa M. Molecularly imprinted polymeric membranes for optical resolution. in Bartsch RA, Maeda M, Eds. Molecular and ionic recognition with imprinted polymers (ACS Symposium Series 703). Washington DC: ACS 1998, pp. 170-187.

[15] Yoshikawa M. Molecularly imprinted polymeric membranes. Bioseparation 2002; 10: 277-86. http://dx.doi.org/10.1023/A:1021537602663

[16] Chronakis IS, Jakob A, Hagström B, Ye L. Encapsulation and selective recognition of molecularly imprinted theophylline and $17 \beta$-estradiol nanoparticles within electrospun polymer nanofibers. Langmuir 2006; 22: 8960-5. http://dx.doi.org/10.1021/la0613880

[17] Yoshimatsu K, Ye L, Lindberg J, Chronakis IS. Selective moleculer adsorption using electrospun nanofiber affinity membranes. Biosens Bioelectron 2008; 23: 1208-15.

http://dx.doi.org/10.1016/j.bios.2007.12.002

[18] Chronakis IS, Milosevic B, Frenot A, Ye L. Generation of molecular recognition sites in electrospun polymer nanofibers via moleculer imprinting. Macromolecules 2006; 39: 357-61. http://dx.doi.org/10.1021/ma052091w

[19] Yoshikawa M, Tanioka A, Matsumoto H. Molecularly imprinted nanofiber membranes. Curr Opin Chem Eng 2011; 1: $18-26$. http://dx.doi.org/10.1016/j.coche.2011.07.003

[20] Yoshikawa M, Higuchi A. Enantioselective membranes in Hoek EMV, Tarabara VV, Eds. Encyclopedia of membranes and technology. New York: Wiley 2013. DOI: 10.1002/9781118522318.emst131

[21] Yoshikawa M, Nakai K, Matsumoto H, Tanioka A, Guiver MD, Robertson GP. Molecularly imprinted nanofiber membranes from carboxylated polysulfone by electrospray deposition. Macromol Rapid Commun 2007; 28: 2100-5.

http://dx.doi.org/10.1002/marc.200700359

[22] Sueyoshi Y, Fukushima C, Yoshikawa M. Molecularly imprinted nanofiber membranes from cellulose acetate aimed for chiral separation. J Membr Sci 2010; 357: 90-7. http://dx.doi.org/10.1016/j.memsci.2010.04.005

[23] Shiomi K, Yoshikawa M. Multi-stage chiral separation with electrospun chitin nanofiber membranes. Sep Purif Technol 2013; 118: 300-4. http://dx.doi.org/10.1016/j.seppur.2013.07.004

[24] Kawasaki T, Yoshikawa M. Nanofiber membranes from cellulose triacetate for chiral separation. Desal Water Treat 2013; 51: 5080-8.

http://dx.doi.org/10.1080/19443994.2013.768832
[25] Mizushima H, Yoshikawa M, Li N, Robertson GP, Guiver MD. Electrospun nanofiber membranes from polysulfones with chiral selector aimed for optical resolution. Eur Polym J 2012; 48: 1717-25.

http://dx.doi.org/10.1016/j.eurpolymj.2012.07.003

[26] Ramakrishna S, Fujihara K, Teo W-E, Lim T-C, Ma Z. An introduction to electrospinning and nanofibers. Singapore: World Scientific 2005.

[27] Greiner A, Wendorff JH. Electrospinning: a fascinating method for the preparation of ultrathin fibers. Angew Chem Int Ed 2007; 46: 5670-703. http://dx.doi.org/10.1002/anie.200604646

[28] Matsumoto $H$, Tanioka A. Functionality in electrospun nanofibrous membranes based on fiber's size, surface area, and molecular orientation. Membranes 2011; 1: 249-64. http://dx.doi.org/10.3390/membranes 1030249

[29] Yoshikawa M, Izumi J. Chiral recognition sites converted from tetrapeptide derivatives adopting racemates as print molecules. Macormol Biosci 2003; 3: 487-98.

http://dx.doi.org/10.1002/mabi.200350016

[30] Yoshikawa M, Ooi T, Izumi J. Alternative molecularly imprinted membranes from a derivative of natural polymer, cellulose acetate. J Appl Polym Sci 1999; 72: 493-9. http://dx.doi.org/10.1002/(SICI)10974628(19990425)72:4<493::AID-APP5>3.0.CO;2-U

[31] Yoshikawa M, Koso K, Yonetani K, Kitamura S, Kimura S. Optical resolution of amino acid derivatives with molecularly imprinted membranes bearing oligopeptide tweezers. J Polym Sci: Part A: Polym Chem 2005; 43: 385-96. http://dx.doi.org/10.1002/pola.20504

[32] Hatanaka M, Nishioka Y, Yoshikawa M. Polyurea with Llysinyl residues as components: Application to membrane separateon of enantiomers. Macromol Chem Phys 2011; 212: 1351-9. http://dx.doi.org/10.1002/macp.201100054

[33] Hatanaka M, Nishioka Y, Yoshikawa M. Polyurea bearing Llysinyl residue as a chiral building block and its application to optical resolution. J Mater Sci Res 2012; 1(No. 4): 114-22. http://dx.doi.org/10.5539/jmsr.v1n4p114

[34] Hatanaka M, Nishioka Y, Yoshikawa M. Chiral polyurea with L-lysinyl residue aimed for optical resolution. J Membr Sci Technol 2013; 2: 109-19. http://dx.doi.org/10.6000/1929-6037.2013.02.02.1

[35] Hatanaka M, Nishioka Y, Yoshikawa M. Chiral separation with polyurea membrane consisting of L-lysinyl residue; Proposal of facile method for prediction of permselectivity. $J$ Appl Polym Sci 2013; 128: 123-31. http://dx.doi.org/10.1002/app.38141

[36] Yoshikawa M, Izumi J, Ooi T, Kitao T, Guiver MD, Robertson GP. Carboxylated polysulfone membranes having a chiral recognition site induced by an alternative molecular imprinting technique. Polym Bull 1998; 40: 517-24. http://dx.doi.org/10.1007/s002890050285

[37] Kondo Y, Yoshikawa M, Okushita H. Molecularly imprinted polyamidee membranes for chiral recognition. Polym Bull 2000; 44: 517-24. http://dx.doi.org/10.1007/s002890070073

[38] Taniwaki K, Hyakutake A, Aoki T, Yoshikawa M, Guiver MD, Robertson GP. Evaluation of the recognition ability of molecularly imprinted materials by surface plasmon resonance (SPR) spectroscopy. Anal Chim Acta 2003; 489: 191-8. http://dx.doi.org/10.1016/S0003-2670(03)00760-8

[39] Sun Y, Li L-Y, Dong X-Y. Multistage affinity ross-flow filtration: process optimization. Bioprocess Eng 1997; 16: 229-35.

http://dx.doi.org/10.1007/s004490050313 
[40] Romero J, Zydney AL, Staging of affinity ultrafiltration processes for chiral separation. J Membr Sci 2002; 209: 10719.

http://dx.doi.org/10.1016/S0376-7388(02)00283-1
[41] Higuchi A, Higuchi Y, Furuta K, Yoon BO, Hara M, Maniwa S, Saitoh M, Sanui K. Chiral separateon of phenyl by ultrafiltration through immobilized DNA membranes. J Membr Sci 2003; 221: 207-18.

http://dx.doi.org/10.1016/S0376-7388(03)00263-1

Received on 28-09-2016

Accepted on 10-10-2016

Published on 26-10-2016

DOI: http://dx.doi.org/10.6000/1929-6037.2016.05.03.3

(C) 2016 Shiomi and Yoshikawa; Licensee Lifescience Global.

This is an open access article licensed under the terms of the Creative Commons Attribution Non-Commercial License (http://creativecommons.org/licenses/by-nc/3.0/) which permits unrestricted, non-commercial use, distribution and reproduction in any medium, provided the work is properly cited. 